\title{
Children's acquisition of discourse markers in English, Hindi, Mandinka and Spanish: Effects of optionality, grammaticalization and narrative elicitation
}

\author{
Vishakha Shukla, Madeleine Long and Paula Rubio-Fernandez \\ University of Oslo
}

We compared the production of discourse markers by 5 -year-old children and adults across four languages: Hindi, English, Mandinka and Spanish. As predicted, Experiment 1a revealed that obligatory markers are acquired earlier, resulting in more adult-like referential expressions. Interestingly, Hindi appears to be undergoing a process of grammaticalization of their numeral 'one' into an indefinite article, which resulted in a protracted acquisition of the corresponding discourse function. Supporting this hypothesis, Experiment $1 \mathrm{~b}$ revealed that older adults from a rural area failed to use the numeral to introduce new characters, whereas 10-year-old children's production was comparable to that of younger adults in the city and higher than 5-year-olds'. Experiment 2 revealed that Mandinka speakers made full use of the markers available in their language when tested on a familiar story, without pictorial prompts. These findings highlight the importance of using culturally-appropriate tasks and diverse samples when investigating the acquisition of discourse-pragmatic functions.

Keywords: discourse markers; new/given referents; grammaticalization; narrative elicitation; pragmatics.

*Corresponding author: paula.rubio-fernandez@ifikk.uio.no 
Keeping track of referents in discourse requires monitoring which referents are new and which referents are given. In English, for example, a discourse referent can be marked as new through the use of an indefinite article (e.g., 'This morning we saw a cat in the garden'), and later be marked as given by using a pronoun or a definite article (e.g., 'When it saw us, the cat got scared and ran away'). Languages vary in the way in which they mark new and given referents, not only in form (e.g., whether they use articles or other nominal markers with the same function) but also in optionality (i.e. the degree to which discourse markers are optional or obligatory). By their very nature, optional discourse markers are used less consistently than obligatory ones, resulting in greater variability in the input that children receive. Optionality has indeed been found to affect children's acquisition of discourse markers, with obligatory markers emerging earlier than optional ones (Berman \& Slobin, 1994; Hickmann et al., 1996). Here we studied children's production of discourse markers across four typologically distinct languages - English, Hindi, Mandinka and Spanish, which differ in the degree to which the marking of new and given referents is optional.

Language acquisition studies normally adopt a synchronic viewpoint, treating languages as fixed systems that young children must acquire through exposure. However, we know from diachronic linguistics that languages are constantly in flux (Heine \& Kuteva, 2006). Thus, studying the acquisition of discourse markers in languages where articles are in the process of being grammaticalized, not only sheds light on how optionality affects acquisition, but also offers a window into the emergence of the new/given distinction in a speech community. This was therefore one of the aims of our study.

Heine (1997) proposed five stages in the process of grammaticalization of the numeral 'one' into an indefinite article: (i) the word 'one' is only used as a numeral; ii) it used to introduce characters in the discourse; iii) it is used to mark specific indefiniteness; iv) it is used to mark non-specific indefiniteness, and $v$ ) it is completely grammaticalized as an indefinite article occurring with all types of nouns. Since character introduction occurs early in the process of grammaticalization, languages at this stage do not yet mark all new discourse referents, resulting in children receiving an inconsistent input. MacWhinney (2001) proposed a model to explain the acquisition of form-function mappings in 
terms of cue reliability, defined as the conditional probability that an interpretation X (e.g., new referent) should be selected given the presence of a cue Y (e.g., the use of a numeral). MacWhinney's model predicts that forms with the highest cue reliability will be the strongest determinants of processing in adults (i.e. out of various possible interpretations, adults will default to the most frequent one) and therefore be acquired earlier. Along similar lines, we hypothesize that young learners of languages in which numerals are in the process of being grammaticalized as newness markers will demonstrate a protracted acquisition of this particular form-function mapping relative to children who acquire languages with fully-grammaticalized indefinite articles.

Against this background, we investigated the effect of cross-linguistic differences in both optionality and grammaticalization on children's acquisition of discourse markers. To do so, we compared children's narratives in four languages from four different families: thus, English and Spanish require the use of indefinite articles to introduce new discourse characters, whereas Hindi lacks an article system. However, Dayal (2018) has recently argued that the numeral 'ek' (one) can be used to introduce new discourse referents in Hindi, and it is frequently used with that discourse function, although it does not satisfy all diagnostic semantic tests for indefinite articles (Chierchia, 1998). Here we hypothesized that Hindi is in the second stage of Heine's (1997) grammaticalization scale (i.e. the numeral 'one' can be used to introduce new discourse characters), and investigated the frequency with which 'ek' is used with that narrative function, and how grammaticalization affects the acquisition of this discourse marker. Finally, unlike English, Spanish and Hindi, Mandinka does not distinguish new and given referents, but instead has a default lexical marker '-o'.

In order to investigate children's acquisition of discourse markers, we elicited picture-based narratives from both children and adults in each of the four languages. Interestingly, while visual narratives are generally presumed to be highly accessible (and thus used in children books, comics, instructions, etc.) research suggests that the interpretation of images as sequential events is an acquired skill that requires exposure and practice (Cohn, 2019). Thus, differences in cultural background (e.g., between cultures with a strong oral story-telling tradition vs a picture book tradition) could result in the 
interpretation of each image as an isolated event rather than a continuous story. This lack of continuity would in turn affect the way in which characters are referred to, as the same character might be treated as a new referent in each picture and be marked accordingly (Fussell \& Haaland, 1978; Cook, 1980; Núñez et al., 2012). Since Mandinka has a strong oral story-telling tradition, but not such a strong picture book tradition, we were interested in whether pictures presented on a computer screen would be interpreted as disconnected images, and whether this type of interpretation would affect the marking of discourse referents. Thus, in addition to using pictures to elicit narratives across the four languages in our sample, we also asked adult speakers of Mandinka to tell a traditional story from memory to see whether their marking of discourse referents might be influenced by the way in which the story was elicited.

In what follows, we provide an overview of cross-linguistic differences in the marking of new and given discourse referents and summarize developmental patterns that have been reported in the literature, which informed our research questions and predictions with regards to the languages chosen for this study. Following this, we discuss children's acquisition of discourse functions in narratives and describe each of the referential systems in the languages included in our study.

\section{The marking of discourse status across languages}

Languages have different ways of marking whether a discourse referent is new or familiar. Some markings operate directly on the noun phrase and are therefore known as local markers (e.g., articles in English; 'A boy and a girl were playing in the field. The boy was wearing a red cape.'). Besides articles, numerals, demonstratives and classifiers are also commonly used as local markers. Markings operating at the sentence level are known as global markings. For example, in Chinese, all new referents occur in post-verbal position. Other common examples of global markings are clefting (e.g., 'It was the father who opened the door') and dislocations ('They adopted the puppy, John and Mary').

Studies on children's comprehension of morphological markings have reported that local markers are easier to process than global markings (Berman et al., 1994). Indeed, children face less 
comprehension difficulties in morphologically-rich languages like Turkish, which rely on local markers to specify the grammatical role of the noun, as compared to morphologically poor languages like English, which rely more on word order (Ammon \& Slobin, 1979; Slobin, 1981, 1985; Slobin \& Bever, 1982). This pattern is also reflected in the acquisition of local markers of newness, which children acquire before global markings (Hickmann et al., 1996; Hickmann \& Hendriks, 1999). These studies compared the use of local markers, such as indefinite articles, to the use of global markings, such as clause structure, to introduce and maintain discourse referents in four languages: English, Chinese, French and German. In all of these languages, local markers emerged earlier than global markings, and the use of clause structure with those functions remained infrequent until the age of 7.

Local and global discourse markings can be obligatory or optional in a language. For example, English requires the obligatory use of articles to mark (in)definiteness, while languages like Hindi and Chinese allow for the optional use of numerals and demonstratives with the same function. Similarly, global markings can be either obligatory or optional. For example, in English, an existential construction like 'There is a dog in the garden' can be used to introduce a new referent, but its use is optional. By contrast, in Chinese, it is obligatory that all new referents are mentioned in post-verbal position. In general, obligatory markings are acquired before optional markings. In an extensive cross-linguistic investigation of the development of narrative functions, Berman and Slobin (1994) observed that functions that are expressed by obligatory markings tend to emerge earlier, at around 3 years.

Locality and obligatoriness facilitate the acquisition of discourse markers to different extents as is evident from the findings of Hickmann et al. (1996) in English, French, German and Chinese. Chinese uses optional local markers such as classifiers and numerals for new referents, but it is obligatory that they occur post-verbally. Hickmann et al. observed that optional local markers of newness are infrequent in all the languages included in their study until 5 years of age, and they emerged in Chinese as early as in the other three languages (all of which use articles obligatorily). Interestingly, the obligatory global markings emerged later than the optional local markers in Chinese, becoming frequent by age 7. Hickmann et al. (1996) argue that the delayed acquisition of global markings (even when 
obligatory) is due to their functional complexity since there is no one-to-one mapping between sentence position and discourse function (see also Slobin, 1985; MacWhinney, 2001; Narasimhan \& Dimroth, 2008).

In conclusion, the scope of discourse markings (local vs global) interacts with the requirements of the language (optional vs obligatory) in determining the emergence of those markings in child language acquisition (Schaeffer \& Matthewson,2005; Guasti et al., 2008; Rozendaal \& Baker, 2008; Bassano, 2015). Local markers, in general, seem to be acquired earlier than global markings, and obligatory markers before optional markers. However, optional local markers can be acquired earlier than obligatory global markings, as Chinese acquisition data show. Thus, while obligatoriness may facilitate marker acquisition, global markings appear to be particularly difficult to acquire, even when they are obligatory. As such, our study focused on local markings in the four languages we tested, and examined the role that optionality plays in the acquisition of those markings. Since previous work suggests that obligatory markings emerge by the age of 3 (Berman and Slobin, 1994) and optional markings are frequently used by the age of 5 (Hickmann et al., 1996), we compared 5-year-olds' use of discourse markers of newness and giveness to their adult counterparts across the four languages.

\section{The acquisition of discourse functions in narratives}

Previous studies on the early stages of acquisition of the new/given distinction focused on spontaneous production in young children's speech (see Hickmann et al., 2015). However, studies focusing on later stages of development recognized the importance of eliciting child data in extended discourse, as it allows for a greater range of variation in referential strategies (for a review, see Berman, 2015). In particular, third person narratives have been frequently used because they allow researchers to test the development of appropriate forms of reference for different functions. Bamberg $(1986,1987)$ identified three discourse functions in narratives: (i) introductions for new characters, (ii) maintenance for referents that have been mentioned in the immediately preceding context, and (iii) reintroduction for referents that have been mentioned before but not in the immediately preceding context. All languages 
typically have preferred linguistic forms for these functions. For example, English typically uses indefinite articles for character introductions, pronouns for maintenance and definite forms for reintroduction. Typically, forms specifying more lexical information (e.g., an indefinite noun phrase) are used for referents that are not highly accessible in the discourse, while forms that encode less lexical information (e.g., light forms such as pronouns or null elements) are used for highly accessible referents.

Many studies have found that children as young as 3 years use pronouns appropriately for character maintenance (Hickmann et al., 1999; Vion \& Colas, 1999; Wong \& Johnston, 2004). Moreover, young children rarely use pronouns to introduce new characters, opting for indefinite and definite nominals to mark that function; however, they often use pronouns inappropriately for character reintroductions. Results from studies of naturalistic dialogue confirm the above observations (see Orvig et al., 2010), with some studies reporting appropriate use of light forms as early as in the two-word stage (Serratrice, 2005; Hughes \& Allen,2013). Children by the age of 2.5 also demonstrate sensitivity to discourse structure in disambiguating pronominal reference by interpreting pronouns as referring to the most prominent character, established either by the frequency with which the character is mentioned in the story or by its frequency in subject position (Song \& Fisher, 2007). Even findings from cross-linguistic studies of reference in extended discourse report an early sensitivity to discourse continuity and the use of appropriate forms for given characters by the age of 4 , whereas new characters are not introduced appropriately before the age of 7 , and character re-introduction is not mastered until age 10 (Hickmann et al., 1996; Hickmann \& Hendricks, 1999). In conclusion, the results of these studies suggest the following order of acquisition of discourse functions in narratives: Maintenance $>$ Introduction $>$ Reintroduction.

In addition, a closer comparison of the acquisition of appropriate markings for these discourse functions across typologically-different languages reveals an effect of the linguistic properties of the systems. Indeed, Aksu-Koc and Nicolopoulou (2014) compared children's use of local and global markings to differentiate new and given referents in three languages: Greek, English and Turkish. Their findings show that children as young as 3 predominantly used indefinite forms for character 
introductions in Greek, but they did not do so until the age of 5 in Turkish (which uses global markings) and in English (which has weaker constraints on article use than Greek).

Finally, children's use of referential forms in narratives is also influenced by the previous discourse and by the listener's perceptual access to the pictures. Children as young as 2.5 - 3.5 years old are sensitive to the type of question used in narrative elicitation. Thus, a predicate-focus question (e.g., "What is X doing?") is more likely to elicit a lighter form of reference (such as a pronoun or null element), compared to an event-focus question (e.g., "What is happening?"), which tends to elicit a nominal element (Campbell et al. 2000; Matthews et al. 2006). Studies have also reported that children show a developmental trend in sensitivity to the interlocutor's perceptual access to the pictures, starting around the age of 6 (Hickmann et al., 1996; Serratrice, 2008). Children respond with a greater number of light referential forms when they are narrating the story to an interlocutor who has perceptual access to the pictures, than when they are telling the story to an ignorant interlocutor. However, this is a late emerging sensitivity and is only systematically observed at around age 9.

Since previous studies report earlier sensitivity to discourse structure than to the interlocutor's perceptual access, we used a general event-focus question - 'What is happening here?' - to elicit narratives in contexts with shared perceptual access between the participant and the experimenter.

\section{Marking new-given referents in English, Hindi, Mandinka and Spanish}

Below is a brief description of the referential systems of the languages included in our study: English

Articles are grammaticalized in English. Indefinite articles are mandatory to introduce new referents, and given referents are marked by definite articles or through the use of pronominal forms. Bare nouns are used for mass nouns (e.g., rice, water) and for generic readings of plural nouns (e.g., 'Tigers live in jungles'). Demonstratives can also optionally be used to mark givenness. There is no gender or number agreement in articles, and only number agreement in demonstratives. Global markings like subject-verb inversions are also used in certain contexts to mark newness (e.g., 'Dancing in the rain was a girl'). 
Hindi

Hindi is an Indo-Aryan language spoken in the Indian subcontinent. It has a relatively free word-order with SOV as the default. It does not have a formal article system and optional local markers (such as numerals, demonstratives and case markings), as well as optional global markings (such as word order variations) can be used to mark the givenness of a referent. Of the available optional local markers, the numeral 'ek' (one) is most frequent for marking new referents and it has even been claimed that it is required to introduce discourse characters (Dayal, 2018). Here we hypothesize that Hindi is in the second stage of Heine's (1997) grammaticalization scale; that is, 'ek' can be used to introduce new characters into the discourse. Pronouns and bare nouns are preferred for given characters in Hindi.

\section{Mandinka}

Mandinka is a Mandé language spoken in The Gambia and Senegal, amongst other West African countries. It lacks a formal article system. A nominal marker ' -0 ', which has been variously called a definite marker or default marker, occurs obligatorily with all nouns, unless another determiner is used in its place, or the sentential context justifies its absence. Historically, it evolves from the demonstrative 'woo'. Creissels (forthcoming) argues that at some point in the evolution of the language, '-o' probably marked definiteness but lost that function over time (for a classic study of this pattern of language change in other African languages, see Greenberg, 1978). Nowadays, the default marker '-o' does not mark (in)definiteness. Demonstratives can be optionally used in Mandinka to mark given information. Pronouns do not encode gender and cannot be omitted in subject position.

Spanish

The article system is grammaticalized in Spanish, with articles being inflected for gender and number. It is obligatory to use indefinite articles to introduce new characters, and definite forms or pronouns are used to refer to characters that are already established in the discourse. Unlike in English, the definite article is used to express generics (e.g., 'Los tigres viven en la jungla'). Spanish is a pro-drop language and pronouns in subject position are therefore often omitted. 
The optionality of the available discourse markers varies across the four languages in our study. Thus, the relative optionality of newness markers is the following: Mandinka > Spanish > English > Hindi. Mandinka is highly consistent in its lack of new/given markers and employs a default lexical morpheme for all nouns. Spanish and English both have obligatory article systems, but Spanish has fewer permissible uses of bare nouns compared to English. Finally, Hindi does not have any obligatory markers but does optionally use certain markers with this function. This makes newness marking in Hindi more inconsistent than in the other languages. Given the results of previous research on the acquisition of new/given markers in narrative-elicitation tasks (Hickmann et al., 1996; Hickmann \& Hendricks, 1999; Serratrice, 2005; Hughes \& Allen, 2013) and the grammatical characteristics of the referential systems of the languages investigated, we made the following predictions:

Regarding the marking of new discourse referents, we predicted that 5-year-old children would have acquired adult-like use of the default lexical marker in Mandinka. In Spanish, we predicted that children of the same age would have close to adult-like performance because indefinite articles are obligatory for introducing new characters in Spanish and bare nouns are less acceptable than in English. Thus, we precited that English-speaking 5-year-old children would be less adult-like in their use of indefinite articles than Spanish-speaking children because indefinite articles are obligatory, but bare nouns are more permissible than in Spanish (reducing the cue reliability of the indefinite article). Finally, we predicted that 5-year-old Hindi-speaking children would differ the most from adults, since marking new referents with the numeral 'one' is optional and therefore less frequent (possibly because it is in the process of being grammaticalized as an indefinite article).

Regarding the marking of given referents, we did not expect any developmental differences across the sampled languages. This prediction is informed by numerous studies showing that the use of pronouns to refer to given discourse entities is mastered early on in the acquisition of discoursepragmatic skills (see Hickmann et al., 2015). We therefore expected that 5-year-old children would demonstrate adult-like use of light referential forms for given characters across the four languages. 


\section{Experiment 1a}

\section{Methods}

\section{Participants}

Four groups of 20 children (English: $M=5 ; 5$, range: 5;0 - 5;11; Hindi: $M=5 ; 7$, range: 4;8 - 6;2; Mandinka: $M=5 ; 5$, range: 5;3 - 6;0; Spanish: $M=5 ; 5$, range: 4;10 - 5;9) and 15 adults who served as controls were recruited from Edinburgh (Scotland), Delhi (India), Brikama (The Gambia) and Asturias (Spain) and tested in their native languages (i.e. English, Hindi, Mandinka and Spanish, respectively). This study was approved by the ethics committee of the University of Oslo and the University of Edinburgh and written informed consent was obtained from each child's parent and each adult participant prior to testing.

\section{Materials and procedure}

A series of fourteen pictures were created featuring one or two animal characters carrying out actions (see Supplementary Materials). A total of six possible characters - a bunny (female), a duck (female), a goose (female), a dog (male), a pig (male), and a woodpecker (male) were randomly combined to create the pictures. The pictures were shown one at a time on a computer screen and depicted sequential series of events (e.g., Panel 1 showed a dog reading in bed and Panel 2 showed the same dog falling asleep in the same setting; see Supplementary Materials), as well as isolated events (e.g., a woodpecker collecting firewood in Panel 9). Characters appeared consecutively in 2-5 pictures. Of interest was the way in which children marked new characters (who had not yet been introduced) and familiar characters (who had already been introduced) relative to adults across the four languages. During the task, participants were told they would see a series of pictures with animals on the computer screen and were asked to tell the experimenter what was happening in each picture. If the participant did not mention any of the characters, one follow-up question was given: 'What else is going on?' Participants' responses were audio recorded for transcription and coding purposes.

\section{Coding}

Given that the selected languages vary in how they mark new and given information, we created the following coding system for analysis purposes (see Table 1). Within the context of a narrative, ' $A$ ' 
responses are appropriate for marking new characters, whereas ' $\mathrm{B}$ ' and ' $\mathrm{C}$ ' responses are appropriate for marking familiar characters.

Table 1. Coding of new and given markings in each of the languages

\begin{tabular}{ccccc}
\hline Coding & Mandinka & Hindi & English & Spanish \\
\hline A & Bare noun & Numeral one & Indefinite & Indefinite \\
\hline B & Demonstrative + noun & Bare noun & Definite & Definite \\
\hline C & Pronoun & Pronoun & Pronoun & Pronoun (overt or not) \\
\hline
\end{tabular}

\section{Results}

\section{Model 1: Marking new characters}

Using logistic mixed effects regression, we modelled the binary outcome variable of Marking $(A=1, B$ and $\mathrm{C}=0$ ) for New Characters, with Age Group (Adult, Child), and Language (Hindi, English, Mandinka, Spanish) as predictor variables. Deviation coding was used for Age (Adult=-.05, Child=.05) and language was dummy-coded with Hindi as the reference level because we predicted that children would perform more similarly to adults in the other three languages. The alpha level for all reported tests in the study (Experiment $1 \mathrm{a}, 1 \mathrm{~b}$ and 2 ) was set to $\mathrm{p}<.05$ and all analyses were run using $\mathrm{R}$ statistical software (R Core Team, 2019). All models were fit with the maximal random effect structure for Participants and Items (Barr, 2013). As predicted, results revealed clear cross-linguistic developmental differences in the marking of new characters (see Table 2 for descriptive statistics; for the full model output, see Supplementary Materials).

Table 2. Rates of A markers for new characters across age groups and languages

\begin{tabular}{ccccc}
\hline Language & Age Group & Mean & SD & Range \\
\hline \multirow{2}{*}{ Hindi } & Children & .10 & .30 & $0-1$ \\
& Adults & .61 & .49 & $0-1$ \\
\hline \multirow{2}{*}{ English } & Children & .65 & .48 & $0-1$ \\
& Adults & .80 & .40 & $0-1$ \\
\hline \multirow{2}{*}{ Spanish } & Children & .89 & .31 & $0-1$ \\
& Adults & .89 & .31 & $0-1$ \\
\hline \multirow{2}{*}{ Mandinka } & Children & 1 & 0 & $0-1$ \\
& Adults & 1 & 0 & $0-1$ \\
\hline
\end{tabular}


There were no main effects or interactions for Mandinka relative to Hindi. However, this is unsurprising given the complete uniformity in responses brought about by the ceiling effect in Mandinka-speaking children and adults as shown in the table above (mean=1, SD=0). For both Spanish and English, on the other hand, there was a main effect of Language relative to Hindi (both p's<.0001), with more A responses for new characters in Spanish and English than in Hindi. As predicted, there was an Age $\times$ Spanish interaction relative to Hindi $(p=.017)$, driven by a significant difference in A responses for Hindi-speaking children and adults $(p=.002)$ but no difference in Spanish-speaking children and adults ( $p=.565)$. We did not find an Age $x$ English interaction relative to Hindi $(p=.113)$. However, as shown in Fig. 1 below, Hindi-speaking children and adults differed the most, followed by Englishspeaking children and adults, then Spanish-speaking children and adults, and finally Mandinka-speaking children and adults, whose responses were identical.

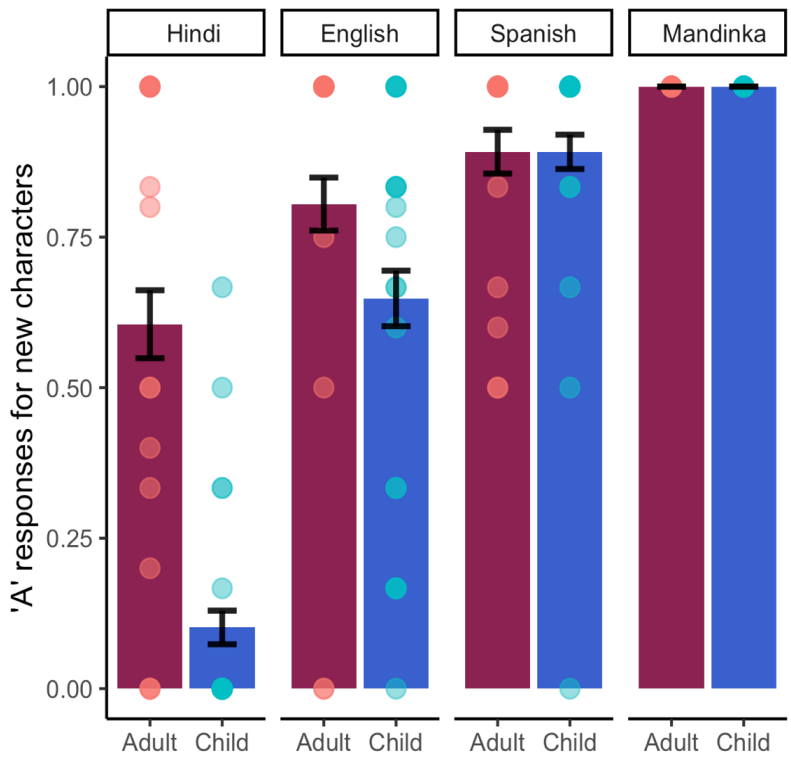

Figure 1. Mean proportions of A markers for new characters across ages in each of the four languages.

Error bars represent 95\% confidence intervals and points reflect participant means.

\section{Model 2: Marking familiar characters}

Using logistic mixed effects regression, we modelled the binary outcome variable of Marker $(A=0, B$ and C=1) for Familiar characters, with Age Group (Adult, Child), and Language (Hindi, English, Mandinka, 
Spanish) as predictor variables. Deviation coding was used for Age (Adult=-.05, Child=.05) and in keeping with the previous model, language was again dummy coded with Hindi as the reference level. As predicted, there were no Age $x$ Language differences in the way familiar characters were marked (see Table 3 for descriptive statistics; for full model output see Supplementary Materials).

Table 3. Rate of B \& C markers for familiar characters across age groups and languages

\begin{tabular}{ccccc}
\hline Language & Language Group & Mean & SD & Range \\
\hline \multirow{2}{*}{ Hindi } & Children & .94 & .23 & $0-1$ \\
& Adults & .95 & .21 & $0-1$ \\
\hline \multirow{2}{*}{ English } & Children & .84 & .36 & $0-1$ \\
& Adults & .74 & .44 & $0-1$ \\
\hline \multirow{2}{*}{ Spanish } & Children & .71 & .45 & $0-1$ \\
& Adults & .93 & .25 & $0-1$ \\
\hline \multirow{2}{*}{ Mandinka } & Children & .10 & .30 & $0-1$ \\
& Adults & .06 & .23 & $0-1$ \\
\hline
\end{tabular}

The lack of Age $x$ Language interactions relative to Hindi demonstrates that by the age of 5 , cross-linguistic developmental differences in the marking of familiar characters are not pronounced (see Fig. 2). However, there was a main effect of Spanish $(p=.0485)$, English $(p=.003)$, and Mandinka $(p<.0001)$ relative to Hindi because there were more overall $B$ and $C$ responses for familiar characters in Hindi than in the other languages.

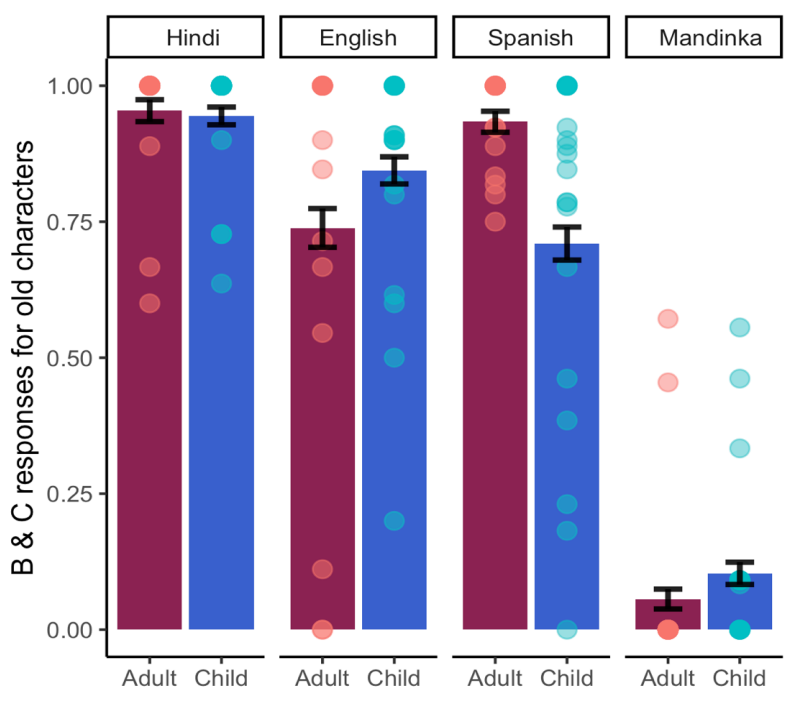

Figure 2. Mean proportions of $\mathrm{B}$ and $\mathrm{C}$ markers for familiar characters across ages in each of the four languages. Error bars represent 95\% confidence intervals and points reflect participant means. 
Model 3: Use of definite articles vs pronouns when marking familiar characters in English and Spanish It is well-documented that young children use pronouns to mark giveness before they start using definite articles (e.g., Hickmann et al., 1999; Vion \& Colas, 1999; Wong \& Johnston, 2004; Orvig et al., 2010). Here we were interested in testing this effect in our English and Spanish data, since both languages have pronouns and definite articles. For this analysis, we focused on the subset of data in which children and adults responded with either definite articles or pronouns when marking familiar characters.

Using logistic mixed effects regression, we modelled the binary outcome variable of Definite article (Definite article=1, Pronoun=0) for Familiar characters, with Age Group (Adult, Child), and Language (English, Spanish) as predictor variables. Deviation coding was used for Age (Adult=-.05, Child=.05). As predicted, our results revealed a main effect of Age $(p=.015)$, with children using definite articles less than adults (see Table 4 for descriptive statistics; for full model output see Supplementary Materials).

Table 4. Rates of definite article use for familiar characters across age groups in English and Spanish

\begin{tabular}{lcccc}
\hline Language & Age Group & Mean & SD & Range \\
\hline \multirow{2}{*}{ English } & Children & .35 & .48 & $0-1$ \\
& Adults & .83 & .38 & $0-1$ \\
\hline \multirow{2}{*}{ Spanish } & Children & .53 & .50 & $0-1$ \\
& Adults & .61 & .49 & $0-1$ \\
\hline
\end{tabular}

The age effect was more prominent in English, where an Age $x$ Language interaction $(p=.006)$ revealed an age-related difference in the use of definite articles for English speakers ( $p=.005)$, but not for Spanish speakers $(p=.829)$ (see Fig. 3). These results suggest that 5-year-old English-speaking children have a preference for pronouns over definite articles compared to their adult counterparts, whereas 5-year-old Spanish-speaking children use definite articles to a similar extent as Spanishspeaking adults. We interpret this difference in the light of numerous cross-linguistic studies showing that determiners emerge earlier in Romance than in Germanic languages, with determiner omission 
occurring more frequently and lasting longer in Germanic languages (e.g., Guasti et al., 2008; Rozendaal \& Baker, 2008; Bassano et al., 2011). The typological contrast between Romance and Germanic languages is interesting because both types of languages use obligatory determiners with nouns (allowing bare nouns only in certain contexts) but differ along a number of features that are consistent with an earlier development of determiners in Romance languages (for discussion, see Bassano, 2015).

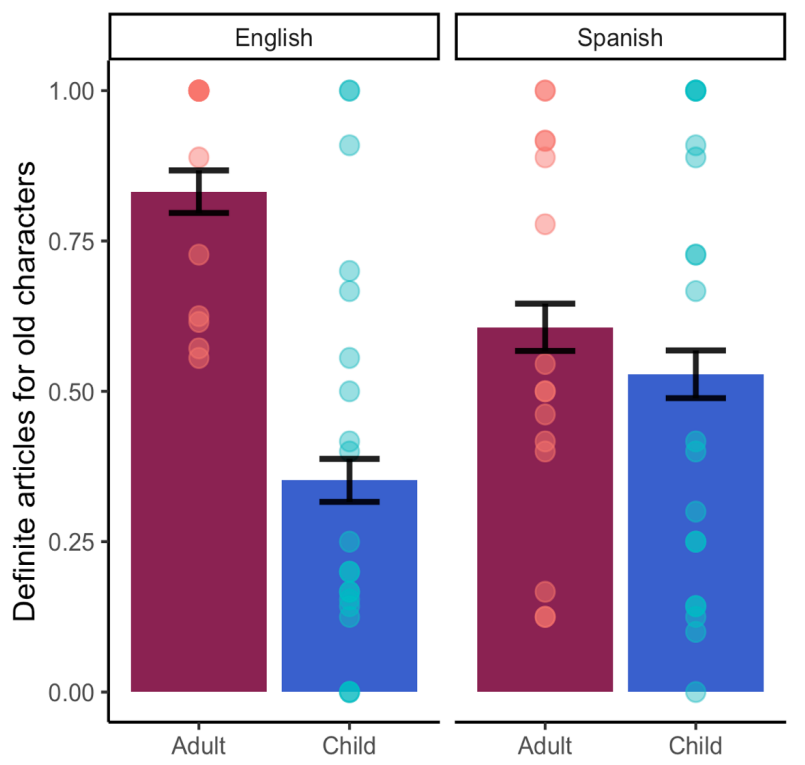

Figure 3. Mean proportions of definite articles for familiar characters across ages in English and Spanish.

Error bars represent 95\% confidence intervals and points reflect participant means.

\section{Experiment 1b}

The first experiment revealed that 5-year-old Hindi-speaking children marked new characters less frequently than English- and Spanish-speaking children of the same age. Hindi has the option of using the numeral 'ek' (one) to introduce discourse characters, but it does not have indefinite articles (Kachru, 1980; Dayal, 2004, 2018). The diachronic process whereby numerals are grammaticalized into indefinite articles has been documented in many languages (see Lyons, 1999), and we hypothesized that Hindi may be currently undergoing the same process. Such a grammaticalization process would explain why Hindi-speaking adults used the numeral 'ek' less frequently than Spanish- and English-speaking adults 
used the indefinite singular article to introduce new characters, which would in turn explain the protracted acquisition of this discourse function in Hindi-speaking children.

Among other sources, grammaticalization processes can result from language contact (Heine \& Kuteva, 2006). For example, a recent study by Otwinowska et al. (under review) reported that PolishEnglish bilingual children produce more definite markings than Polish monolingual children when telling stories in Polish. Since Polish does not have articles, the authors interpret this finding as a language transfer effect, whereby the bilingual children are trying to compensate for the lack of a definite article in Polish by using demonstratives and possessives. Since the Hindi-speaking adults in Experiment $1 \mathrm{a}$ were all proficient English speakers from the Delhi area, we wanted to investigate whether a similar transfer effect might be the cause of their relatively frequent use of the numeral 'ek' to introduce new characters in Hindi. For this purpose, we collected more Hindi data from a small town in a neighboring state where people tend to have a poorer command of English. On average, this group of adult participants was also older than the first group from the city (40 year old vs 25 year old, on average).

We were also interested in whether older children would use the optional marker 'ek' in adultlike ways. According to MacWhinney (2001), children's acquisition of a form-function mapping should be influenced by the frequency of its input, so we expected Hindi-speaking children to acquire the character introduction function of the numeral 'ek' later than children speaking languages with obligatory newness markers. Given that children have acquired the most sophisticated referential devices in a language by age 10 (e.g., the ability to appropriately reintroduce characters using definite articles; Hickmann et al., 2015), we tested a group of 10-year-old Hindi-speaking children in Delhi to see whether their use of ' $\mathrm{ek}^{\prime}$ in the narrative task was comparable to that of adults.

\section{Methods}

\section{Participants}

Fifteen native Hindi-speaking adults (Mean age: 40) were recruited from Allahabad, India. All participants had at most functional proficiency in English, and used it in very restricted domains. Twenty 
children of age $10(M=10 ; 6$; range: 9;8-11;0) were recruited from the same school in Delhi as in Experiment 1a. These children were learning English in school but were not proficient nor did they use English outside the classroom.

\section{Materials and procedure}

The materials and procedure from Experiment 1a were used again in Experiment 1b.

\section{Results}

Model 4: The role of age and English influence on the marking of new characters in Hindi

Using logistic mixed effects regression, we modelled the binary outcome variable of Use of 'Ek' ('Ek'=1, B and $C=0$ ) for New characters in Hindi, with Group (5 year-olds in Delhi, 10 year-olds in Delhi, Adults in Delhi, and Adults outside Delhi) as the predictor variable. Group was dummy-coded with Adults in Delhi as the reference level because we wanted to compare adults and children from Delhi, and adults from Delhi with adults from outside of Delhi. Results revealed clear evidence for children's protracted acquisition of 'ek' when introducing new characters, and for the cross-linguistic influence of English in adults' use of this numeral as an indefinite article (see Table 5 for descriptive statistics; for the full model output, see Supplementary Materials).

Table 5. Rates of uses of 'ek' to introduce new characters in Hindi across age groups and regions

\begin{tabular}{lccc}
\hline \multicolumn{1}{c}{ Groups } & Mean & SD & Range \\
\hline Adults in Delhi & .61 & .49 & $0-1$ \\
5-year-olds in Delhi & .10 & .30 & $0-1$ \\
10-year-olds in Delhi & .64 & .48 & $0-1$ \\
Adults outside Delhi & .05 & .22 & $0-1$ \\
\hline
\end{tabular}

There was a main effect of 5 -year-olds relative to adults in Delhi $(p=.0004)$, such that 5 -yearolds used 'ek' less often than their adult counterparts (see Fig. 4). This difference disappeared by the age of 10, as 10-year-olds and adults in Delhi did not differ in their use of the numeral to introduce new characters $(p=.810)$. The model also revealed a main effect of adults outside Delhi relative to adults in Delhi $(p=.0006)$, such that adults outside of Delhi used 'ek' much less frequently than those in Delhi, 
suggesting that the use of 'ek' may be influenced by Hindi-speakers' knowledge and use of English in urban areas.

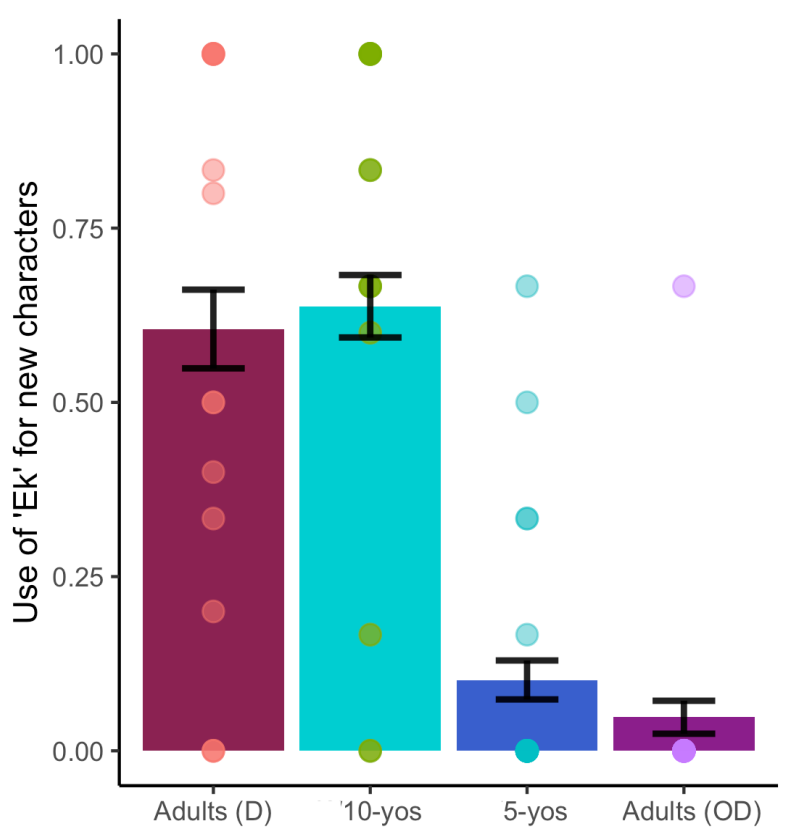

Figure 4. Mean proportions of uses of 'ek' for new characters across ages and locations. 'Adults (D)' refers to adults in Delhi and 'Adults (OD)' refers to adults outside Delhi. Error bars represent 95\% confidence intervals and points reflect participant means.

\section{Experiment 2}

Following up on the findings from Mandinka speakers in Experiment 1a, we investigated whether the method used for eliciting narratives played a role in the referential forms chosen by those participants. Both children and adult Mandinka speakers used o-marked nouns for both new and familiar referents despite the option of using pronouns in that language. A quick look through The Gamble Archive (19462003), which is a rich collection of work on the history and culture of The Gambia by Professor David Gamble, shows that the use of pronouns is actually very common in Mandinka. This led us to investigate whether the lack of pronoun use in our data was due to the specific task employed for eliciting narratives. Various methodological issues have been shown to contribute to differences in the results obtained with narrative elicitation tasks. Factors such as the number of characters in the story, the perceptual access of the interlocutor, the form of the probing questions (e.g., 'What is happening?' vs 
'What is X doing?') and the animacy of characters have all been shown to have an effect on both children's and adults' responses (Hickmann et al., 1996; Matthews et al., 2006; Aksu-Koç \& Nicolopoulou, 2014).

We hypothesized that the reason why Mandinka speakers used full nominals for all characters was due to their treatment of each picture as independent from the others (i.e. participants were not linking the panels as cohesive events). Interestingly, we observed a similar pattern of behavior in 3 English-speaking adults, who also treated the pictures as independent events and repeatedly referred to familiar characters using an indefinite article (see Fig. 2). From a cultural perspective, picture storytelling requires familiarity with a series of conventions that need to be mastered before a 'successful reading' of the materials can be elicited (Cohn, 2019). Therefore, we wanted to further investigate whether the lack of pronouns observed with Mandinka speakers in Experiment 1a was due to the use of an unfamiliar task. Thus, in the last experiment of the study, we collected oral stories from a few native speakers of Mandinka without any pictorial prompt. Given the cultural significance of story-telling in West Africa, re-telling of oral narratives should reveal a more naturalistic use of pronouns than picture story-telling.

\section{Methods}

\section{Participants}

A total of five Mandinka speaking adults (Mean age: 42) were recruited from Brikama, The Gambia. Written informed consent was obtained from each participant prior to testing.

\section{Materials and procedure}

Participants were asked to tell the popular story below, in their own words. Only the title of the story was given as a prompt.

\section{The greedy lion}

A lion once went hunting and found a rabbit. He caught the rabbit and started heading home but, on the way, he saw an antelope. The lion got greedy and decided to leave 
the rabbit and go for the antelope instead, but the antelope outran him. The lion came back to get the rabbit, but the rabbit was gone too. He then went home on an empty stomach

\section{Results}

As shown in Figures 5 and 6 , adult Mandinka speakers showed sensitivity to the distinction between main vs. secondary characters when choosing appropriate referential forms in traditional narratives. Participants also seemed to mark referents differently according to the discourse functions of narratives: character introduction, maintenance and reintroduction. Indeed, speakers unanimously preferred '-o' forms over pronouns for introducing new characters. However, pronouns were always used to refer to the main character (the lion) once it had been introduced, whereas o-marked nouns were preferred for referring to secondary characters, even when they had already been introduced.

Those instances where participants used full nouns for reference maintenance were contexts where primary and secondary characters were competing for pronominal reference (e.g., 'It catches a rabbit. It says the rabbit will make a good dinner', where 'it' refers to the primary character, the lion). This could be a form of audience design whereby people were avoiding ambiguity, since Mandinka pronouns are not marked for gender.

The results of Experiment 2 are generally consistent with adult data from other cross-linguistic studies (Bamberg, 1987; Hickmann \& Hendricks, 1999). We can therefore conclude that the surprisingly infrequent use of pronouns that was observed in child and adult Mandinka speakers in Experiment 1a was likely a result of treating each panel as an independent picture, probably because of their limited experience with picture story-telling (particularly from a computer screen). 


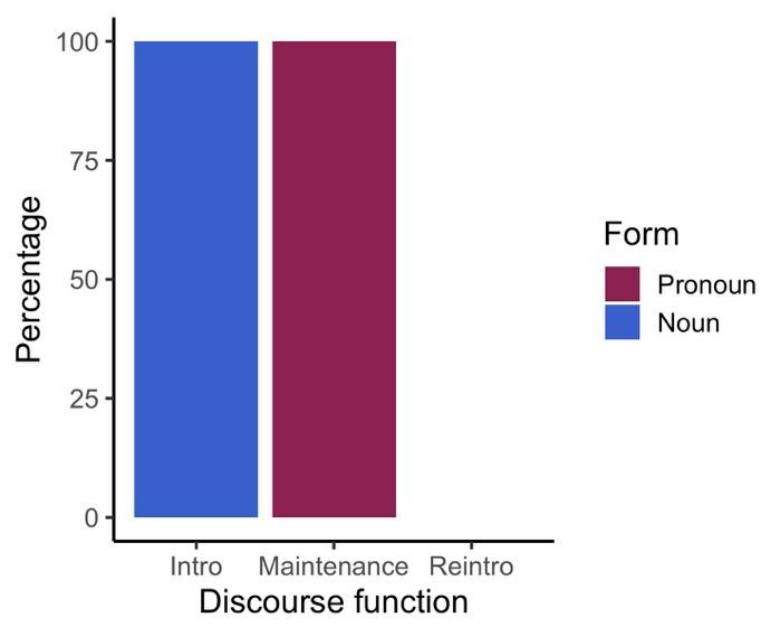

Figure 5. Percentages of o-marked nouns and pronouns used to introduce, maintain reference to and reintroduce the main character in a traditional oral narrative by adult speakers of Mandinka.

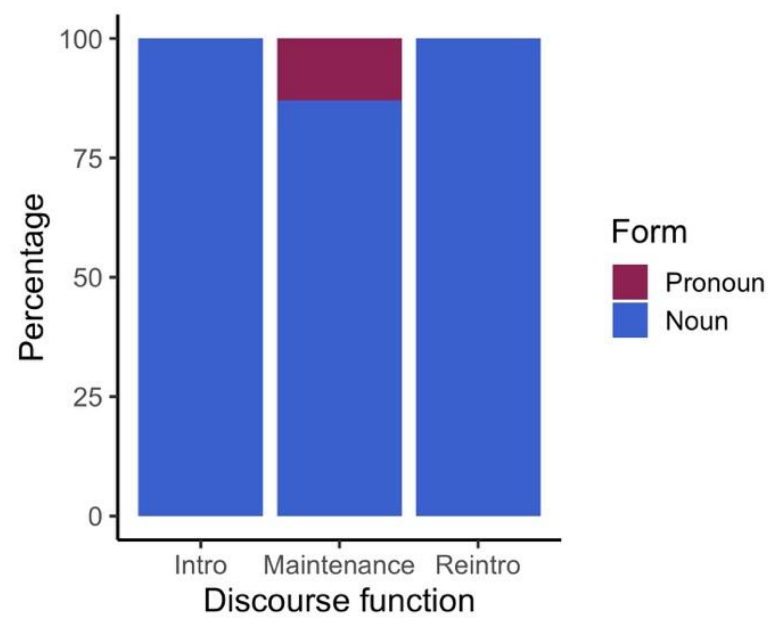

Figure 6. Percentages of o-marked nouns and pronouns used to introduce, maintain reference to and reintroduce the secondary characters in a traditional oral narrative by adult speakers of Mandinka.

\section{General discussion}

According to Hickmann et al. (2015), cross-linguistic comparisons are necessary before generalizations can be made about early vs. late mastery of reference on a universal basis (p.204). In this study, we investigated a typologically diverse set of languages allowing us to explore the role of input in the acquisition of discourse-pragmatic functions of different discourse markers. Our initial prediction regarding the acquisition of newness markers was that they would be influenced by the consistency 
with which they are used in adult language (MacWhinney, 2001). Our results confirmed that the use of discourse markers emerged earlier in languages that consistently used them for the same functions. As predicted, children produced the most adult-like descriptions in Mandinka, given the uniform use of omarked nouns (irrespective of discourse status) in adult responses. Hindi-speaking 5-year-olds, on the other hand, demonstrated the least adult-like performance, which was also expected given that Hindispeaking adults are the least consistent in their use of newness markers amongst the four language groups. Results from Spanish and English also fell in line with our predictions, showing that children in both of these languages use appropriate newness markers (i.e. indefinite articles) in a more adult-like way than Hindi-speaking children, and within those two languages, Spanish-speaking children have the most adult-like performance. The latter pattern is expected because of the difference in consistency with which articles are used in the two languages: Spanish has more restrictions on the use of bare nouns than English does, with Spanish-speaking children arguably getting exposure to a more consistent use of articles, which in turn facilitates the form-to-function mapping of indefinite articles onto the newness discourse function (see also Bassano, 2015).

The results of our study did not reveal developmental cross-linguistic differences in the use of givenness markers. This confirmed our prediction, which was based on evidence that children as young as 3 years old are able to use correct referential forms for character maintenance (Wong \& Johnston, 2004; Song \& Fisher, 2007), while 5-year-old children already demonstrate adult-like performance.

\section{Cue reliability and the late mastery of newness marking in Hindi-speaking children}

The findings from Experiments $1 \mathrm{a}$ and $1 \mathrm{~b}$ support the hypothesis that the newness marking function of

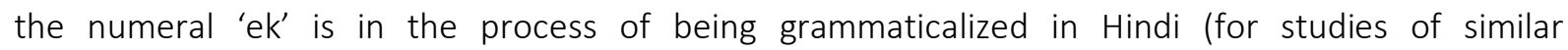
grammaticalization processes in Chinese and Polish, see Wong, 2016; Hwaszcz \& Kędzierska, 2018). We found evidence for this hypothesis in the first experiment, where Hindi-speaking adults did not use 'ek' to mark new characters as frequently as Spanish and English adults used indefinite articles with that function. Moreover, results from the second experiment revealed that not all Hindi-speaking adults 
mark discourse status using 'ek', with younger adults from Delhi producing higher rates than older adults from a more rural area. This pattern of results could be due to the interaction between the age factor (e.g., the grammaticalization process might be more evident in the speech of the younger generation) and the degree of language contact (e.g., the different levels of exposure to English). Further comparisons of different populations are necessary to understand the extent to which these factors contribute to this potential grammaticalization process in Hindi.

The findings with adults suggest a plausible interpretation of the developmental data: 5-yearold Hindi-speaking children differed markedly from their English and Spanish counterparts because the input they receive from adults is rather inconsistent, possibly because the meaning of the numeral 'ek' is in flux at the moment. Despite the inconsistency in the input, we did observe that Hindi-speaking children acquire the newness marking function of the numeral 'ek' by at least the age of 10 . Future developmental work comparing children between the ages of 5-10 across different languages undergoing this change (e.g., Chinese and Polish; see Wong, 2016; Hwaszcz \& Kędzierska, 2018) could help us understand the extent of the delay experienced by children acquiring a system of discourse markers undergoing a grammaticalization process, compared to children learning a fullygrammaticalized system.

The effect of narrative elicitation techniques

Many researchers have pointed out the implications of methodological heterogeneity for the comparability of studies on the acquisition of pragmatic markers in extended discourse (see Hickmann et al., 2015). Usually, heterogeneity emerges from both linguistic and cognitive factors (e.g., the question type used for prompting, the number of characters present in the scene, whether the experimenter and the participant share knowledge, etc.). However, there are also cultural factors that could influence participants' performance: narratives involve the use of decontextualized language (i.e. language that abstracts away from the here-and-now) and the conventions used to interpret the narrative situation are highly culture-specific. Unsurprisingly, research has shown cross-cultural 
differences in narrative performance by both children and adults (Gorman et al. 2011; Carmiol \& Sparks, 2014), even though the use of picture stimuli for narrative elicitation has been a common practice in both linguistic and psychological research. Interestingly, Cohn (2019) has recently argued that the interpretation of sequential images as a cohesive whole might not be universal, but rather dependent on exposure to the system of graphics in a culture. The stark contrast between the use of pronouns by Mandinka speakers when describing a pictorial narrative (Experiment 1a) versus retelling a folk story from memory (Experiment 2) offers support to Cohn's argument.

While we have no estimates of how frequent picture-book reading is in The Gambia, we suspect it may not be as common as in Europe or middle-class India. The fact that the pictures were presented on a computer screen (rather than in an actual book), may also contribute to participants' interpretation of the pictures as unrelated. Either way, the results of the last experiment unequivocally showed that adult Mandinka speakers made full use of the markings available in their language when tested on a familiar story, without pictorial prompts. Therefore, our findings highlight the importance of using culturally-appropriate tasks and diverse samples in cross-linguistic studies of the emergence of discourse-pragmatic functions.

\section{Acknowledgements}

This research was supported by a Researcher Project from the Research Council of Norway (Ref. 275505) awarded to PRF. All authors gratefully acknowledge this funding. Special thanks to Fatoumata Jallow for all her help with data collection, transcription and translation in The Gambia. Thanks also to the schools and children who participated in the study.

\section{References}

Aksu-Koç, A., \& Nicolopoulou, A. (2014). Character reference in young children's narratives: A crosslinguistic comparison of English, Greek, and Turkish. Lingua, 155, 62-84. 
Ammon, M. S., \& Slobin, D. I. (1979). A cross-linguistic study of the processing of causative sentences. Cognition, 7, 3-17.

Bamberg, M. G. (1986). A functional approach to the acquisition of anaphoric relationships. Linguistics, $24,227-284$.

Bamberg, M. G. (1987). The acquisition of narratives: Learning to use language. Berlin: Walter de Gruyter.

Barr, D. J. (2013). Random effects structure for testing interactions in linear mixed-effects models. Frontiers in Psychology, 4, 328.

Bassano, D. (2015). The acquisition of nominal determiners: Evidence from crosslinguistic approaches. In L. Serratrice and S. E. M. Allen (Eds.), The acquisition of reference, TiLAR 15 (pp. 25-49). Amsterdam/Philadelphia: John Benjamins Publishing Company

Bassano, D., Maillochon, I., Korecky-Kröll, K., van Dijk, M., Laaha, S., Dressler, W. U., \& van Geert, P. (2011). A comparative and dynamic approach to the development of determiner use in three children acquiring different languages. First Language, 31, 253-279.

Berman, R. (2015). Language development and use beyond the sentence. In E. Bavin and L. Naigles (Eds.), The Cambridge Handbook of Child Language (pp. 458-480). Cambridge: Cambridge University Press.

Berman, R. A., \& Slobin, D. I. (1994). Different ways of relating events in narrative: A crosslinguistic developmental study. Hillsdale, NJ: Lawrence Erlbaum.

Campbell, A. L., Brooks, P., \& Tomasello, M. (2000). Factors affecting young children's use of pronouns as referring expressions. Journal of Speech, Language, and Hearing Research, 43, 1337-1349.

Carmiol, A. M., \& Sparks, A. (2014). Narrative development across cultural contexts. In D. Matthews (Ed.), Pragmatic development in first language acquisition (pp. 279-296). Philadelphia, PA: John Benjamins Publishing Company.

Chierchia, G. (1998). Reference to kinds across language. Natural Language Semantics, 6, 339-405. 
Cohn, N. (2019). Structural complexity in visual narratives: Theory, brains, and cross-cultural diversity. In M. Grishakova and M. Poulaki (Eds.), Narrative complexity and media: Experiential and cognitive interfaces (pp. 174-199). Lincoln: University of Nebraska Press.

Cook, B. L. (1980). Picture communication in the Papua New Guinea. Educational Broadcasting International, 13, 78-83.

Creissels, D. (forthcoming). A sketch of Mandinka. To appear in F. Lüpke (Ed.), The Oxford guide to the Atlantic languages of West Africa. Oxford: Oxford University Press

Dayal, V. (2004). Number marking and (in)definiteness in kind terms. Linguistics and Philosophy, 27, $393-450$

Dayal, V. (2018). (In)definiteness without articles: Diagnosis, analysis, implications. In G. Sharma and R. Bhatt (Eds.), Trends in Hindi Linguistics (pp. 1-26). Berlin: Mouton de Gruyter.

Fussell, D., \& Haaland, A. (1978). Communicating with pictures in Nepal: Results of practical study used in visual education. Educational Broadcasting International, 11, 25-31.

Gamble, D. P. (1997). Mandinka Stories from Books Published Prior to 1960. In Gambia Studies Series by Professor David Gamble. Library Special Collections, Charles E. Young Research Library, UCLA

Gorman, B. K., Fiestas, C. E., Peña, E. D., \& Clark, M. R. (2011). Creative and stylistic devices employed by children during a storybook narrative task: A cross-cultural study. Language, speech, and hearing services in schools, 42, 167-181.

Greenberg, J. H. (1978). How does a language acquire gender markers. Universals of Human Language, 3, 47-82.

Guasti, M. T., Gavarró, A., De Lange, J., \& Caprin, C. (2008). Article omission across child languages. Language Acquisition, 15, 89-119.

Heine, B. (1997). Cognitive foundations of grammar. Oxford: Oxford University Press.

Heine, B., \& Kuteva, T. (2006). The changing languages of Europe. Oxford: Oxford University Press.

Hickmann, M., \& Hendriks, H. (1999). Cohesion and anaphora in children's narratives: A comparison of English, French, German, and Mandarin Chinese. Journal of Child Language, 26, 419-452. 
Hickmann, M., Hendriks, H., Roland, F., \& Liang, J. (1996). The marking of new information in children's narratives: A comparison of English, French, German and Mandarin Chinese. Journal of Child Language, 23, 591-619.

Hickmann, M., Schimke, S., \& Colonna, S. (2015). From early to late mastery of reference: Multifunctionality and linguistic diversity. In L. Serratrice and S. E. M. Allen (Eds.), The acquisition of reference, TiLAR 15 (pp. 181-211). Amsterdam/Philadelphia: John Benjamins Publishing Company

Hughes, M. E., \& Allen, S. E. M. (2013). The effect of individual discourse-pragmatic features on referential choice in child English. Journal of Pragmatics, 56, 15-30.

Hwaszcz, K., \& Kędzierska, H. (2018). The rise of an indefinite article in Polish: An appraisal of its grammaticalisation stage. Studies in Polish Linguistics, 13, 145-166.

Kachru, Y. (1980). Aspects of Hindi Grammar. New Delhi: Manohar Publications.

Lyons, C. (1999). Definiteness. Cambridge: Cambridge University Press.

MacWhinney, B. (2001). The competition model: The input, the context, and the brain. In P. Robinson (Ed.), Cognition and Second Language Instruction (pp. 69-90). Cambridge: Cambridge University Press.

Matthews, D., Lieven, E., Theakston, A., \& Tomasello, M. (2006). The effect of perceptual availability and prior discourse on young children's use of referring expressions. Applied Psycholinguistics, 27, 403422.

Narasimhan, B., \& Dimroth, C. (2008). Word order and information status in child language. Cognition, $107,317-329$

Núñez, R., Cooperrider, K., Doan, D., \& Wassmann, J. (2012). Contours of time: Topographic construals of past, present, and future in the Yupno valley of Papua New Guinea. Cognition, 124, 25-35.

Orvig, A. S., Marcos, H., Morgenstern, A., Hassan, R., Leber-Marin, J., \& Parès, J. (2010). Dialogical beginnings of anaphora: The use of third person pronouns before the age of 3. Journal of Pragmatics, 42, 1842-1865. 
Otwinowska, A., Opacki, M., Mieszkowska, K., Białecka-Pikul, M., Wodniecka, Z., \& Haman, E. (under review), Polish-English bilingual children overuse referential markers: MLU inflation in Polish language narratives.

Rozendaal, M. I., \& Baker, A. E. (2008). A cross-linguistic investigation of the acquisition of the pragmatics of indefinite and definite reference in two-year-olds. Journal of Child Language, 35, $773-807$.

Schaeffer, J., \& Matthewson, L. (2005). Grammar and pragmatics in the acquisition of article systems. Natural Language \& Linguistic Theory, 23, 53-101.

Serratrice, L. (2005). The role of discourse pragmatics in the acquisition of subjects in Italian. Applied Psycholinguistics, 26, 437-462.

Serratrice, L. (2008). The role of discourse and perceptual cues in the choice of referential expressions in English preschoolers, school-age children, and adults. Language Learning and Development, 4, 309-332.

Slobin, D. I. (1981). The origin of grammatical encoding of events. In W. Deutsch (Ed.), The child's construction of language (pp. 185-199). London: Academic Press.

Slobin, D. I. (1985). Crosslinguistic evidence for the language-making capacity. In D. I. Slobin (Ed.), The crosslinguistic study of language acquisition (pp. 1157-1256). Lawrence Erlbaum Associates, Inc.

Slobin, D. I., \& Bever, T. G. (1982). Children use canonical sentence schemas: A crosslinguistic study of word order and inflections. Cognition, 12, 229-265.

Song, H. J., \& Fisher, C. (2007). Discourse prominence effects on 2.5-year-old children's interpretation of pronouns. Lingua, 117, 1959-1987.

Team, R. C. (2019). R: A language and environment for statistical computing, Version 3.0. 2. Vienna, Austria: R Foundation for Statistical Computing; 2013.

Vion, M., \& Colas, A. (1999). Expressing coreference in French: Cognitive constraints and development of narrative skills. Journal of Psycholinguistic Research, 28, 261-291. 
Wong, A. L. (2016). Indefinite markers, grammaticalization, and language contact phenomena in Chinese. Proceedings of the Linguistic Society of America, 1, 9-1.

Wong, A. M. Y., \& Johnston, J. R. (2004). The development of discourse referencing in Cantonesespeaking children. Journal of Child Language, 31, 633-660. 